Family Profile No. 17, 2018

\title{
Marriage: More than a Century of Change, 1900-2016
}

\author{
Author: Colette A. Allred
}

The marriage rate for women in the United States has declined greatly since the beginning of the twentieth century, but the rate and magnitude of the decline vary among different demographic groups. Using data from the National Vital Statistics, Decennial Census, and the American Community Survey, this profile analyzes women's marriage patterns in the U.S. since 1900, looking closely at differences among racial and ethnic groups as well as educational attainment groups. This is an update of a previously published family profile: "Marriage: More than a Century of Change" (FP-13-13).

Change in Marriage Rate in the U.S., 1900-2016

- Fewer than half as many women married per thousand unmarried women in 2016 compared to 1900 , with rates of 32.0 and 68.2 , respectively.

- The peak marriage rate of 92.3 , observed in 1920 , is nearly three times the rate in 2016.

- The women's marriage rate decreased steadily from 1970 to 2010 but appears to have reached stability in the last six years, decreasing by only one-tenth of a point between 2010 and 2016.
Figure 1. Women's Marriage Rate, 1900-2016

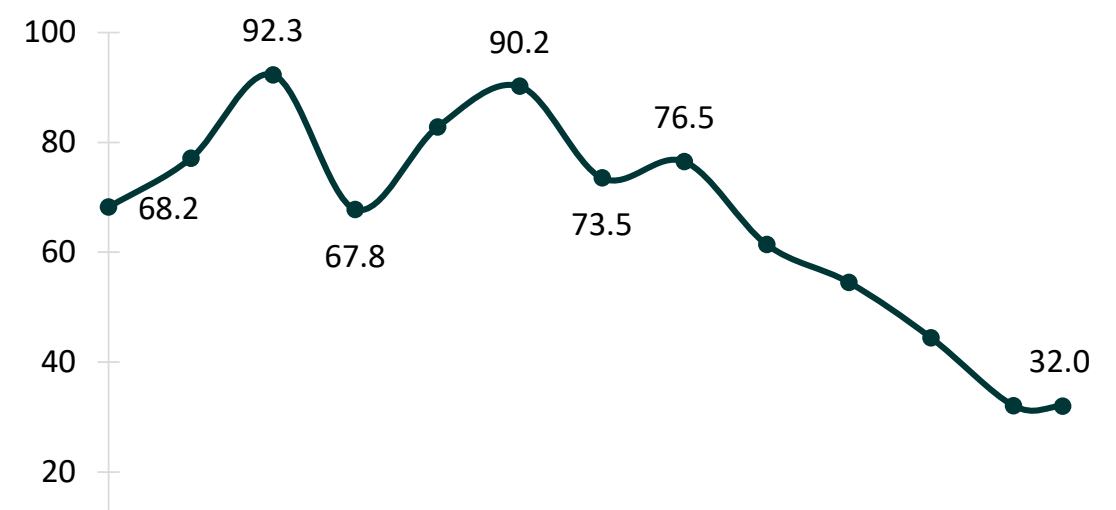

0

Sources: NCFMR analyses of the 1890-1960 data come from National Vital Statistics "100 Years of Marriage and Divorce Statistics United States, 1867-1967" Report. The 1970-1990 data come from the Centers for Disease Control and Prevention/National Center for Health Statistics. The 2000 data come from the National Center for Health Statistics, CDC and the Census Bureau 2000. The 2010 and 2016 data come from the U.S. Census Bureau, American Community Survey.

Note: Data for Alaska begin in 1959. Data for Hawaii begin in 1960.

\section{Change in Marital Status, 1900-2016}

- The percentage of women who are married has decreased since its peak of $65 \%$ in 1960 , with a current level of $46 \%$.

- Over the past 50 years, the share of women who are separated or divorced has increased from around $5 \%$ to nearly $15 \%$.

- The percentage of women who are widowed has remained relatively stable since 1900 , with a slight decrease since 1970.

- Between 2010 and 2016, the percentages of women widowed, separated/divorced, never married, and married have remained fairly stable.
Figure 2. Marital Status of Women, 1900-2016

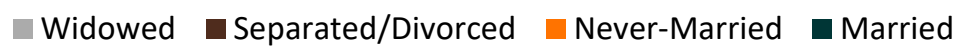

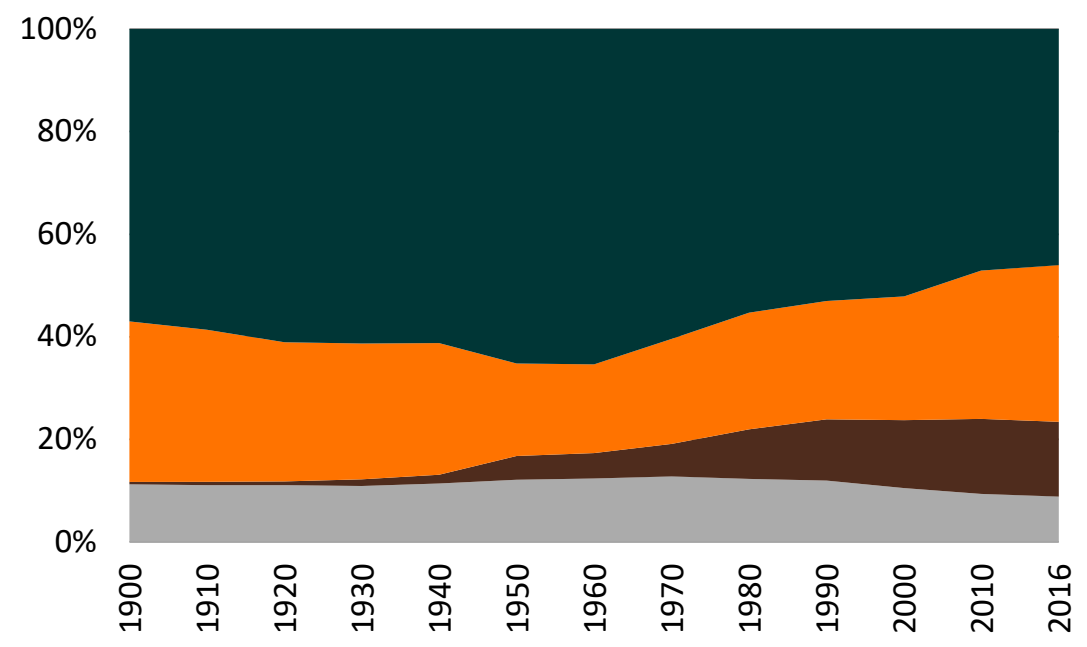

Source: NCFMR analyses of U.S. Census Bureau, Decennial Census, 1900-2010 (IPUMS); U.S. Census Bureau, American Community Survey, 2016 (IPUMS) Note: Data for separated were not available until 1950. 
Variation in Percentage Married According to Race \& Ethnicity, 1940-2016

- In 1940 , around $60 \%$ of women were married regardless of race-ethnicity.

- The percentage of Black women who are married has diverged from the other groups, falling to $26 \%$ by 2016 .

- The percentages of Hispanic and White women who are married have both declined, although to a lesser extent than Black women.

- The percentage of Asian women who are married has remained the most stable throughout the 76 years examined, with $58 \%$ married in 2016.
Figure 3. Percentage of Women Married Among Racial and Ethnic Groups, 1940-2016

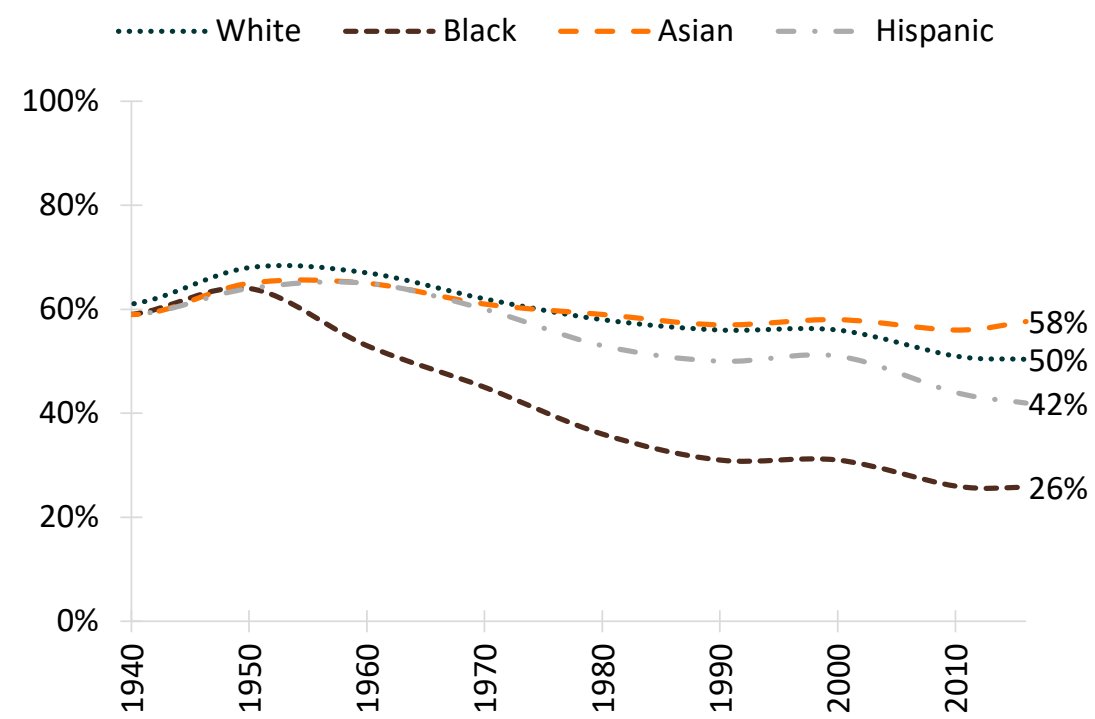

Sources: NCFMR analyses of U.S. Census Bureau, Decennial Census, 1940-2000 (IPUMS); U.S. Census Bureau, American Community Survey, 2010 and 2016 (IPUMS)

\section{Variation in Percentage Married According to Educational Attainment, 1940-2016}

- In 1940 , between $53 \%$ and $63 \%$ of women in all educational attainment groups were married.

- In 2016, the percentages of women who were married in each educational group continued to diverge and ranged from a low of $27 \%$ among those with less than a high school education to a high of $59 \%$ among those with at least a bachelor's degree. The percentages of college graduates who are married has remained steady over a 35 year span.

- The percentages of those with a high school education and those with some college have recently converged and continue to decline, with about $44 \%$ of women in each group married in 2016.
Figure 4. Percentage of Women Married Among Educational Attainment Groups, 1940-2016

$<$ H.S. H.S. - - - Some College - - Bachelor's+

$100 \%$

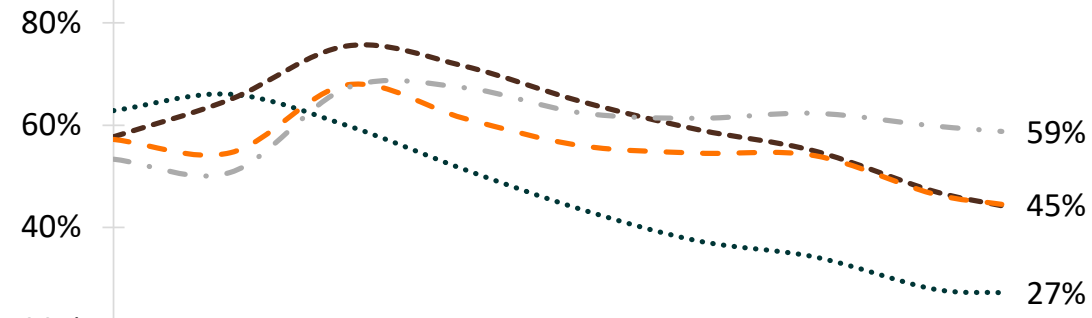

$20 \%$

$0 \%$

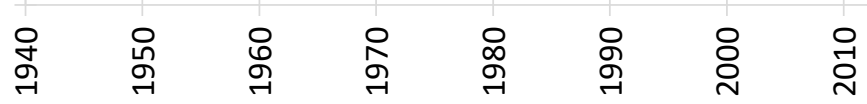

Sources: NCFMR analyses of U.S. Census Bureau, Decennial Census, 1940-2000 (IPUMS); U.S. Census Bureau, American Community Survey, 2010 and 2016 (IPUMS)

\section{References:}

Cruz, J. (2013). Marriage: More than a century of change. Family Profiles, FP-13-13. Bowling Green, OH: National Center for Family \& Marriage Research. https://www.bgsu.edu/content/dam/BGSU/college-of-arts-and-sciences/NCFMR/documents/FP/FP-13-13.pdf

\section{Suggested Citation:}

Allred, C. A. (2018). Marriage: More than a century of change, 1900-2016. Family Profiles, FP-18-17. Bowling Green, OH: National Center for Family \& Marriage Research. https://doi.org/10.25035/ncfmr/fp-18-17.

\section{ReSU. National Center for Family \& Marriage Research}

http://www.bgsu.edu/ncfmr ncfmr@bgsu.edu

(419) 372-3119 